\title{
Cinzas de biomassa geradas na agroindústria do cacau: caracterização e uso em substituição ao cimento
}

\author{
Biomass ash from cocoa agroindustry: characterization \\ and use as a cement substitute
}

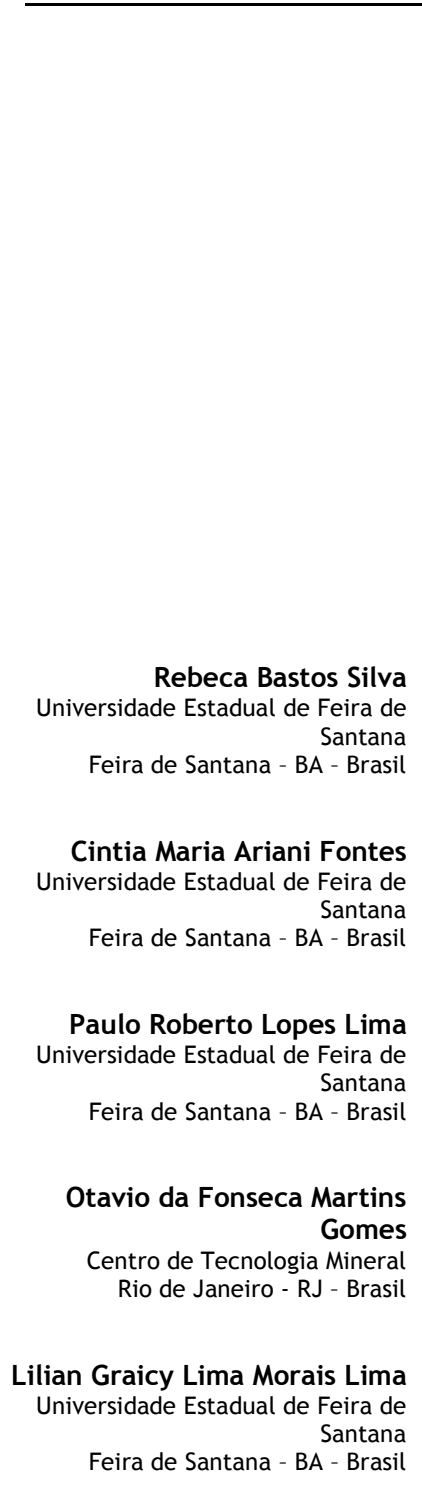

\section{Rebeca Bastos Silva \\ Cintia Maria Ariani Fontes \\ Paulo Roberto Lopes Lima \\ Otavio da Fonseca Martins Gomes \\ Lilian Graicy Lima Morais Lima \\ Ruan Carlos de Araujo Moura \\ Romildo Dias Toledo Filho}

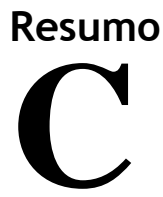

inza de biomassa é um resíduo sólido gerado em grande quantidade em caldeiras para produção de energia e calor. Na indústria de processamento de cacau, que usa casca de amêndoa de cacau (20\%) e madeira de eucalipto $(80 \%)$ como combustível, são geradas cinzas volantes e cinzas de fundo, cujas propriedades são pouco conhecidas, o que limita sua correta disposição ou aplicação. Neste trabalho, cinza fornalha (fundo) e ciclone (volante) foram coletadas, durante o processo de limpeza da caldeira, e caracterizadas quanto a composição química, morfologia (MEV), granulometria e mineralogia (DR-X) com o objetivo de avaliar a potencialidade das cinzas para uso como adição mineral. As cinzas foram beneficiadas com moagem e queima controlada a 500, 700 e $900^{\circ} \mathrm{C}$. Para avaliação do efeito da cinza, foram moldadas quatro argamassas com 5\% de substituição de cimento por cinza ciclone e cinza fornalha, in natura e moídas. Os resultados dos testes de absorção de água e resistência mecânica (compressão e tração na flexão) demonstraram um aumento da absorção e da porosidade para todas as misturas, mas a manutenção das propriedades mecânicas para mistura com cinza ciclone moída, quando comparada com a argamassa sem adição, demonstrando a potencialidade desta cinza como adição mineral.

Palavras-chave: Cinza de caldeira. Adição mineral. Argamassa.

\section{Abstract}

Biomass ash is a solid waste generated in large quantities in stand-alone boilers for the generation of power and heat. The cocoa industry, which uses cocoa almond bark (20\%) and eucalyptus wood (80\%) as fuel, generates fly and bottom ash. The fact that the properties of the ash are little known limits its correct provision and application. In this paper, bottom ash ("fornalha") and fly ash ("ciclone") were collected during the boiler cleaning process, and characterized by their chemical composition, morphology (SEM), particle size and mineralogy $(D R-X)$ in order to assess the potential use of the ash as mineral addition. The ash was treated by grinding and controlled burning at

Ruan Carlos de Araujo Moura Universidade Estadual de Santa Cruz Ilhéus - BA - Brasil

Romildo Dias Toledo Filho Universidade Federal do Rio de Janeiro Rio de Janeiro - RJ - Brasil

Recebido em 01/08/14 Aceito em 02/07/15 500, 700 and $900^{\circ}$ C. To evaluate the effect of ash, four mortars were cast with $5 \%$ cement with fly ash and bottom ash replacement, in natura and ground. The results of water absorption and mechanical strength (compression and tension in flexion) tests showed increased absorption and porosity in all mixtures, but unchanged mechanical properties for mortar with ground fly ash, compared with mortar without addition. This demonstrates that this kind of ash has potential as mineral addition.

Keywords: Boiler ash. Cement replacement addition. Mortar.

SILVA, R. B.; FONTES, C. M. A.; LIMA, P. R. L.; GOMES, O. da F. M.; LIMA, L. G. L. M.; MOURA, R. C. de A.; 


\section{Introdução}

O impacto ambiental negativo gerado pelo uso de combustíveis fósseis, principalmente devido à grande emissão de $\mathrm{CO}_{2}$, tem motivado a busca de soluções energéticas que possam ser renováveis, descentralizadas, e que respeitem os limites naturais do meio ambiente (WORLD..., 2000). No Brasil essa perspectiva de mudança poderá implicar a alteração da matriz energética que reduzirá a participação das usinas a óleo e a gás e aumentará a participação da biomassa como fonte de energia (GREENPACE..., 2007).

A madeira foi a principal fonte de energia da era pré-industrial e permaneceu como o principal combustível em várias regiões do mundo, mesmo após o advento dos combustíveis fósseis. Apesar da gradativa redução do uso de madeira, notadamente aquela oriunda de florestas nativas, a queima de biomassa é ainda a principal matriz energética de vários setores industriais que utilizam caldeira para geração de vapor. A biomassa utilizada atualmente tem sua origem em madeira de reflorestamento e também em resíduos agrícolas, se destacando como um combustível renovável e sustentável (WERTHER et al., 2000; LIM et al., 2102).

A indústria cacaueira produz vários tipos de resíduos de biomassa com potencial para aproveitamento energético, como a poda das árvores, a casca do fruto e a casca (ou tegumento) da amêndoa do cacau. O tegumento de amêndoa do cacau (TAC) é um subproduto da indústria de moagem de cacau e corresponde à casca da semente que é retirada no processo industrial para obtenção do líquor (matéria-prima do chocolate). Uma tonelada de amêndoa com $7 \%$ de umidade pode gerar de $80 \mathrm{~kg}$ a $120 \mathrm{~kg}$ de TAC após o processamento. A produção mundial de cacau para 2013 foi de cerca de 4 bilhões de toneladas, o que resultou em aproximadamente 400 milhões de toneladas de TAC. Na região sul do estado da Bahia, onde estão instaladas cinco indústrias de moagem, são gerados por ano aproximadamente $10.000 \mathrm{t}$ de TAC. Esse resíduo de tegumento tem sido descartado pela indústria ou usado como material combustível (queima em caldeiras) em conjunto com madeira (SODRÉ, 2007). No entanto, o processo de queima de biomassa na agroindústria do cacau gera como resíduo grande quantidade de cinzas, que são retiradas diariamente durante o processo de limpeza da caldeira. Essa cinza residual tem sido disposta dentro das próprias empresas geradoras, o que pode resultar em contaminação do solo ou ar.

Atualmente, a alternativa mais utilizada para aproveitamento da cinza residual da queima de biomassa é adubo, mas, a depender de sua composição química, pode haver contaminação do solo e das culturas. Outra forma de utilização dessas cinzas é como adição mineral em substituição ao cimento, a exemplo da cinza de casca de arroz e da cinza de bagaço de cana, que apresentam alto teor de sílica, o que confere alta reatividade e melhorias nas propriedades físicas e mecânicas do concreto (CORDEIRO; TOLEDO FILHO; FAIRBAIRN, 2009a; RODRIGUES et al., 2013). No entanto, tem-se verificado que algumas cinzas (LIMA; ROSSIGNOLO, 2009) não apresentam contribuição relevante quando usadas como substituição ao cimento em concretos e argamassas.

A ação pozolânica das cinzas depende primariamente da composição química, que deverá conter teores de sílica, alumina e ferro superiores a $70 \%$ (ABNT, 2012; AMERICAN..., 2001). Quando tais cinzas apresentam estrutura mineralógica cristalina sua reatividade é limitada. A ação fíler e pozolânica das cinzas é diretamente influenciada por sua finura, sendo desejável na composição granulométrica a presença de uma quantidade de material retido na peneira de abertura de malha de $45 \mu \mathrm{m}$ inferior a $34 \%$. Para melhorar o desempenho das cinzas de biomassa vários tratamentos vêm sendo aplicados visando aumentar a reatividade desses materiais. A queima das cinzas a altas temperaturas, com o objetivo de promover alteração da estrutura cristalina e aumentar o grau de amorfização dos materiais, e a moagem dos grãos, para aumento de sua finura, têm sido os mais aplicados (CORDEIRO; TOLEDO FILHO; FAIRBAIRN, 2009b; FONTES, 2008; KANNING, 2013; KANNING et al., 2014).

As propriedades da cinza de biomassa e seu efeito sobre os materiais à base de cimento são dependentes de vários fatores, entre eles o tipo de biomassa utilizada e as características da queima (temperatura, tipo de caldeira, etc.). Considerando essa variabilidade, Vassilev et al. (2010) classificaram as cinzas de biomassa em quatro tipos químicos, denominados $\mathrm{S}, \mathrm{K}, \mathrm{C}$ e $\mathrm{CK}$, que dependem da quantidade de determinados compostos predefinidos: teor de $\mathrm{K}_{2} \mathrm{O}+\mathrm{P}_{2} \mathrm{O}_{5}+\mathrm{SO}_{3}$ $+\mathrm{Cl}_{2}$, teor de $\mathrm{CaO}+\mathrm{MgO}+\mathrm{MnO}$ e teor de $\mathrm{SiO}_{2}+$ $\mathrm{Al}_{2} \mathrm{O}_{3}+\mathrm{Fe}_{2} \mathrm{O}_{3}+\mathrm{Na}_{2} \mathrm{O}+\mathrm{TiO}_{2}$.

Entre as cinzas utilizadas na produção de materiais de construção e oriundas de vários tipos de biomassa, como cama de frango - SDBA (OLIVEIRA et al., 2012); casca de arroz - RHA (OLIVEIRA et al., 2012); palha de trigo - WSA (AL-AKHRAS, 2013); madeira - BFA (ESTEVES 
et al., 2012); resíduo de óleo de palma - POFA (TANGCHIRAPAT; JATURAPITAKKUL, 2010); folha de bambu - BL (VILLAR-COCIÑA et al., 2011); bagaço de cana-de-açúcar - BC (CORDEIRO; TOLEDO FILHO; FAIRBAIRN, 2009a); bagaço de azeitona e resíduos agrícolas OPAW (CARRASCO et al., 2014); resíduo de oliva - OW (CUENCA et al., 2013); resíduo de madeira - WW (BAN; RAMLI, 2011); bagaço de azeitona - OP (LEIVA et al., 2009); casca de castanha-de-caju (LIMA; ROSSIGNOLO, 2009), apenas quatro se encontram dentro dos limites para uso como pozolana: SDBA, RHA, POFA e BC. Por isso, a utilização de novas cinzas na construção civil requer a realização de ensaios físicos, químicos e mineralógicos para que se tenha o conhecimento de sua composição química, forma, densidade, granulometria e umidade, que interferem diretamente no desempenho dos materiais cimentícios (PINHEIRO; RENDEIRO; PINHO, 2005).

O objetivo deste trabalho é a caracterização da cinza de biomassa gerada em uma indústria de beneficiamento de cacau com vista a seu uso como adição mineral na produção de argamassas. Foram realizados ensaios de caracterização da cinza, com determinação da composição química, da estrutura mineralógica, da morfologia do grão e granulometria. Foram coletados dois tipos de cinza, cinza ciclone e cinza fornalha, que sofreram beneficiamento com moagem e queima controlada. A influência da substituição de $5 \%$ do cimento por cinza foi avaliada através do ensaio de absorção de água e ensaios mecânicos.

\section{Materiais e métodos}

\section{Cinzas de biomassa}

As cinzas de biomassa utilizadas neste trabalho foram geradas em uma indústria de beneficiamento de cacau (Figura 1a) a partir da queima de cavacos de eucalipto (Figura 1b) e casca de amêndoa de cacau (Figura 1c) na proporção de $80 \%$ e $20 \%$ respectivamente. A cinza é coletada diariamente pelos operadores dentro da fornalha, denominada de cinza fornalha (CF), e nos filtros dos gases, denominada cinza ciclone (CC), sendo armazenada em tambores metálicos. Nessa indústria são geradas em torno de $30 \mathrm{t}$ de cinzas por mês, o que equivale a 360 t de resíduos sólidos por ano.

Inicialmente as cinzas foram submetidas a análise química e mineralógica com o objetivo de avaliar, respectivamente, a composição química e a estrutura cristalina.

As análises químicas foram realizadas por meio da espectroscopia por fluorescência de energia dispersiva de raios $\mathrm{X}$, utilizando equipamento EDX 720. Para as análises mineralógicas foi utilizada a difração de raios $\mathrm{X}$. $\mathrm{O}$ espectro foi coletado pelo método do pó em um equipamento Bruker D8 nas seguintes condições de operação: radiação de cobre $\mathrm{K} \alpha(30 \mathrm{kV} / 40 \mathrm{~mA})$; e velocidade do goniômetro de $0,02^{\circ} 2 \theta$ por passo, com tempo de contagem de $1 \mathrm{~s}$ por passo, e coletados de $5^{\circ}$ a $70^{\circ} \quad(2 \theta)$. Para complementar a análise mineralógica foram realizadas medidas espectrais de reflectância relativa utilizando o espectrorradiômetro portátil ASDFielSpecFullResolution.

Figura 1 - Produção de cinzas: (a) vista da caldeira; (b) cavacos de eucalipto; e (c) cascas das amêndoas de cacau
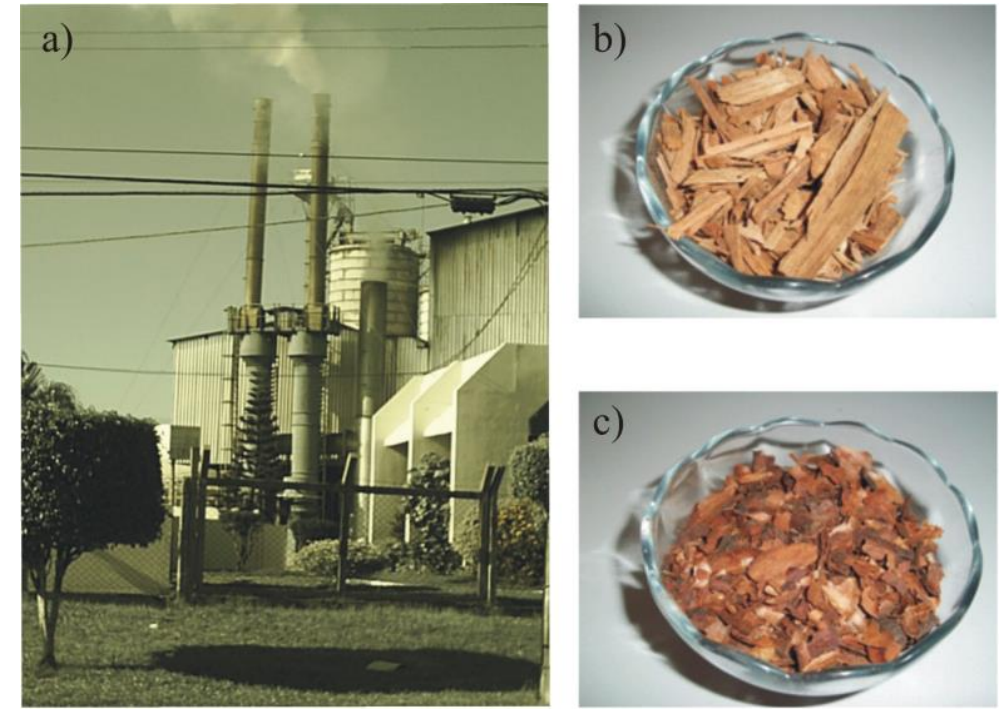
A partir de análises termogravimétricas, as cinzas foram queimadas nas temperaturas de $500{ }^{\circ} \mathrm{C}, 700$ ${ }^{\circ} \mathrm{C}$ e $900{ }^{\circ} \mathrm{C}$ para avaliar possíveis alterações na estrutura cristalina (NAIR et al., 2008).

As cinzas foram moídas nos tempos de 1 min e 3 min em moinho de bolas, com o objetivo de homogeneizar o material (redução de grãos aglomerados) e de reduzir a granulometria para aumentar a reatividade com o cimento.

\section{Cimento e areia}

Foi utilizado cimento $\mathrm{CP}$ II $\mathrm{F} 32$, com massa específica de $2,97 \mathrm{~kg} / \mathrm{m}^{3}$. O agregado miúdo foi uma areia quartzosa proveniente do município de Alagoinhas, BA, com dimensão máxima de 1,2 $\mathrm{mm}$, módulo de finura de 1,83 , massa específica seca de $2,64 \mathrm{~kg} / \mathrm{dm}^{3}$ e absorção de $0,1 \%$.

\section{Argamassas}

As argamassas foram moldadas no traço 1:3 (cimento:areia), em massa, com teor de substituição de cimento por cinza em 5\%. Estudos realizados com outros tipos de cinza de biomassa, como a cinza da casca da castanha-de-caju (LIMA; ROSSIGNOLO, 2009), cinza do bagaço da canade-açúcar (TEODORO et al., 2013), demonstraram redução nas propriedades mecânicas para teores superiores a $5 \%$. O espalhamento das misturas foi mantido dentro do intervalo de $265 \pm 5 \mathrm{~mm}$, medido na mesa de consistência de acordo com a NBR 13276 (ABNT, 2003) (Figura 2a). O fator águacimento foi mantido fixo em 0,51 , e adição de $0,15 \%$ de superplastificante foi necessária para manter a argamassa com cinza com a mesma trabalhabilidade.

Foram produzidas cinco misturas, REF (sem cinza), CC (5\% de cinza ciclone sem calcinação), CC M $(5 \%$ de cinza ciclone moída sem calcinação), CF (5\% de cinza fornalha sem calcinação) e CF M (5\% de cinza fornalha moída sem calcinação). Vale salientar que as cinzas não foram calcinadas por não terem apresentado amorfização com o tratamento térmico. A moagem de 3 min não foi utilizada por não diferenciar-se granulometricamente da cinza moída por $1 \mathrm{~min}$.

Foram moldados corpos de prova cilíndricos com altura de $100 \mathrm{~mm}$ e diâmetro de $50 \mathrm{~mm}$ para ensaio de absorção aos 28 dias de idade, de acordo com a norma NBR 9778 (ABNT, 2005a).

Para ensaio de tração na flexão e compressão (Figuras 2b e 2c) foram moldados corpos de prova prismáticos de dimensão 100x100x400 mm, de acordo com a NBR 13279 (ABNT, 2005b). As propriedades mecânicas foram avaliadas aos 3,7 e 28 dias de idade. Cura por imersão foi realizada em todas as amostras até a data do ensaio.

\section{Resultados e discussão}

\section{Caracterização e beneficiamento das cinzas}

Na Figura 3 são classificadas as cinzas estudadas neste trabalho em comparação com outras cinzas de biomassa já utilizadas em substituição ao cimento e apresentadas na introdução. As composições químicas das cinzas fornalha e cinza ciclone são apresentadas na Tabela 1.

Verifica-se que as cinzas de cacau (CC e CF) são classificadas como tipo $\mathrm{CK}$, com teores de $\mathrm{K}_{2} \mathrm{O}+$ $\mathrm{P}_{2} \mathrm{O}_{5}+\mathrm{SO}_{3}+\mathrm{Cl}_{2}$ entre $30 \%$ e $70 \%$, com teor de $\mathrm{CaO}+\mathrm{MgO}+\mathrm{MnO}$ maior que $30 \%$ e teor de $\mathrm{SiO}_{2}$ $+\mathrm{Al}_{2} \mathrm{O}_{3}+\mathrm{Fe}_{2} \mathrm{O}_{3}+\mathrm{Na}_{2} \mathrm{O}+\mathrm{TiO}_{2}$ menor que $70 \%$ Essas cinzas apresentam classificações similares às cinzas oriundas de biomassa agrícola e biomassa animal (VASSILEV et al., 2013), mas diferente das demais cinzas de biomassa utilizadas na construção civil, que são do tipo $\mathrm{C}$ ou $\mathrm{S}$.

\section{Figura 2 - Ensaios da argamassa: (a) consistência; (b) tração na flexão; e (c) compressão}
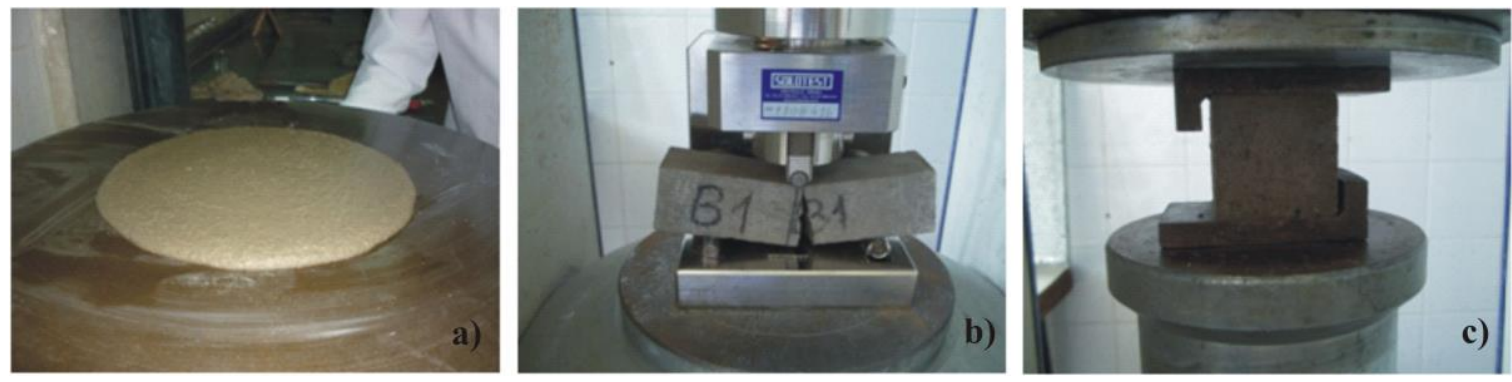

324 Silva, R. B.; Fontes, C. M. A.; Lima, P. R. L.; Gomes, O. da F. M.; Lima, L. G. L. M.; Moura, R. C. de A.; Toledo Filho, R. D. 
Figura 3 - Classificação química de cinzas de diversas fontes de biomassa

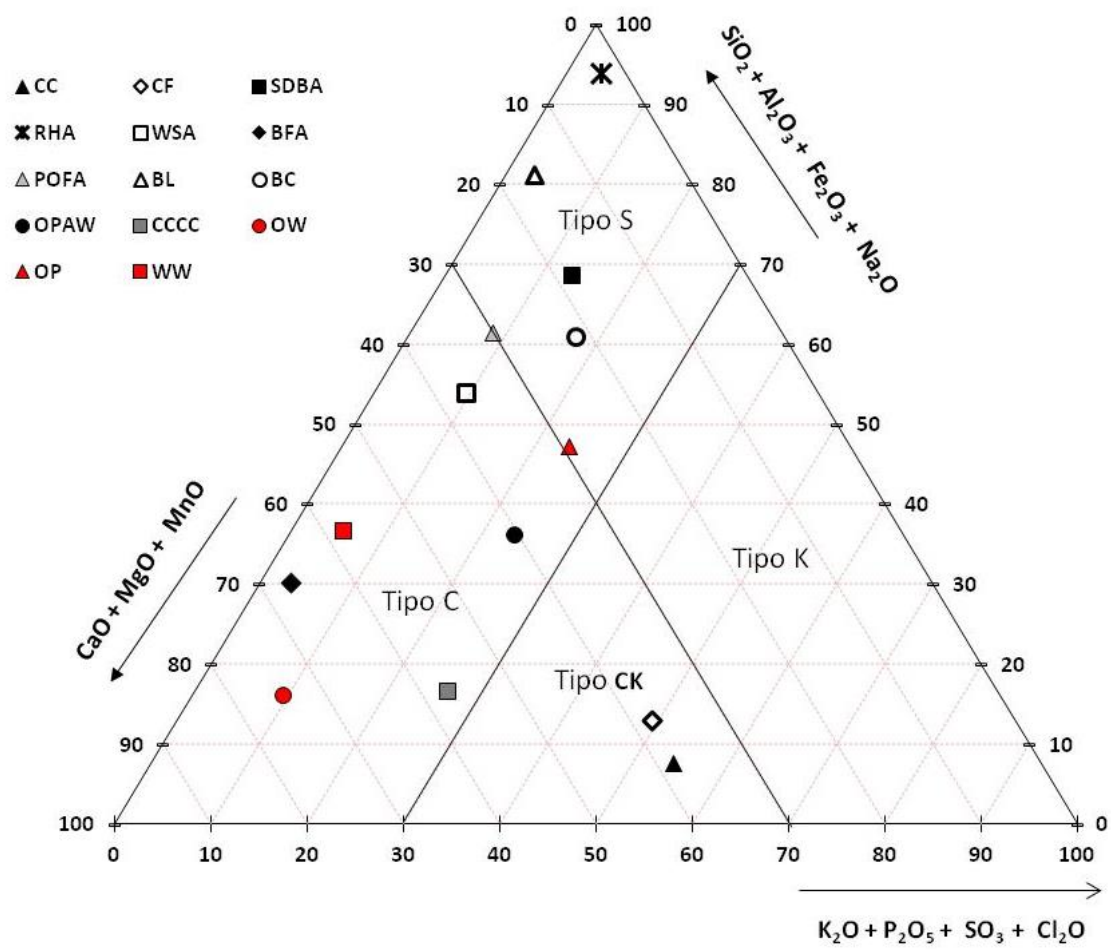

Fonte: baseado em Vassilev (2010).

Tabela 1 - Composição química das cinzas

\begin{tabular}{c|c|c|c|c|c|c|c|c|c|c|c|c|c|c}
\hline Composto & $\mathbf{K}_{2} \mathbf{O}$ & $\mathbf{C a O}$ & $\mathbf{M g O}$ & $\mathbf{P}_{2} \mathbf{O}_{5}$ & $\mathbf{S O}_{3}$ & $\mathbf{F e}_{2} \mathbf{O}_{3}$ & $\mathbf{S i O}_{2}$ & $\mathbf{Z n O}$ & $\mathbf{R b}_{2} \mathbf{O}$ & $\mathbf{M n O}$ & $\mathbf{N a}_{2} \mathbf{O}$ & $\mathbf{T i O}_{2}$ & $\mathbf{A l}_{2} \mathbf{O}_{3}$ & $\mathbf{L O I}$ \\
\hline $\mathrm{CC}(\%)$ & 37,1 & 6,7 & 15,5 & 4,7 & 1,5 & 2,8 & 4,9 & 0,09 & 0,09 & 0,15 & 1,17 & 0,15 & 0,6 & 22,8 \\
$\mathrm{CF}(\%)$ & 32,2 & 8,3 & 15,8 & 11,3 & 1,3 & 2,8 & 10,2 & 0,03 & 0,08 & 0,13 & 0,93 & 0,29 & 1,6 & 15,3 \\
\hline
\end{tabular}

Fazendo uma comparação com a norma EN 450-1 (EUROPEAN..., 2001), que classifica as cinzas volantes quanto a seu uso como adição ao concreto, a cinza de biomassa deveria ser do Tipo $S$ para ser classificada como uma adição pozolânica. Além disso, os teores de álcalis equivalente $\left(\mathrm{Na} 2 \mathrm{O}+0,658 \mathrm{~K}_{2} \mathrm{O}\right)$ devem ser limitados a $5 \%$, o teor de anidro sulfúrico $\mathrm{SO}_{3}$ a $3 \%$ e o teor de cloreto, expresso como $\mathrm{Cl}^{-}$, deve ser menor que $0,1 \%$. Na Figura 4 as cinzas de biomassa utilizadas na produção de materiais de construção são comparadas com os limites da norma EN 450-1 (EUROPEAN..., 2001). Verificase que as cinzas de biomassa não atendem aos teores limites utilizados para cinza volante oriunda da queima de carvão mineral, o que indica que eles podem não ser adequados para limitação do uso de cinza de biomassa em materiais à base de cimento.

As difrações de raios $X$ das cinzas $\mathrm{CC}$ e CF são apresentadas na Figura 5. Verifica-se uma estrutura cristalina, com picos principais relacionados a gismondite $\left(\mathrm{CaAl}_{2} \mathrm{Si}_{2} \mathrm{O}_{8} \cdot 4 \mathrm{H}_{2} \mathrm{O}\right)$. Esse mineral está presente em cinzas volantes oriundas da queima de carvão mineral (ALEXPOULOS et al., 2013). Picos de fosfato de magnésio $\left(\mathrm{Mg}_{2} \mathrm{P}_{2} \mathrm{O}_{7}\right)$ e sulfato de potássio ou arcanita $\left(\mathrm{K}_{2} \mathrm{SO}_{4}\right)$ também foram identificados, assim como traços de óxido de magnésio $(\mathrm{MgO})$, óxido de potássio $\left(\mathrm{K}_{2} \mathrm{O}\right)$ e silicato de cálcio $\left(\mathrm{Ca}_{2} \mathrm{SiO}_{4}\right)$.

Através da DRX verifica-se que as cinzas de biomassa de cacau são cristalinas, e a cinza ciclone apresenta menor cristalinidade. Devido a esse fato, a cinza ciclone foi escolhida para ser submetida a um tratamento térmico, com o objetivo de tentar amorfizar sua estrutura. Na Figura 6 é apresentado resultado da análise termogravimétrica da cinza ciclone. Verifica-se que, como a cinza é resultante da queima há $300^{\circ} \mathrm{C}$, após a perda de água, a uma temperatura de $100{ }^{\circ} \mathrm{C}$, não há nenhuma perda importante de massa até $400{ }^{\circ} \mathrm{C}$. A partir dessa temperatura verifica-se redução da massa e aumento da liberação de energia (DTG), que alcança um pico próximo a $850^{\circ} \mathrm{C}$. Assim, foram definidas as temperaturas de beneficiamento da cinza em $500{ }^{\circ} \mathrm{C}, 700{ }^{\circ} \mathrm{C}$ e $900{ }^{\circ} \mathrm{C}$. 
Figura 4 - Classificação química de cinzas de diversas fontes de biomassa quanto ao limite de álcalis

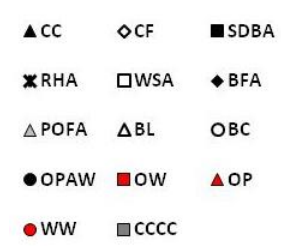

BA

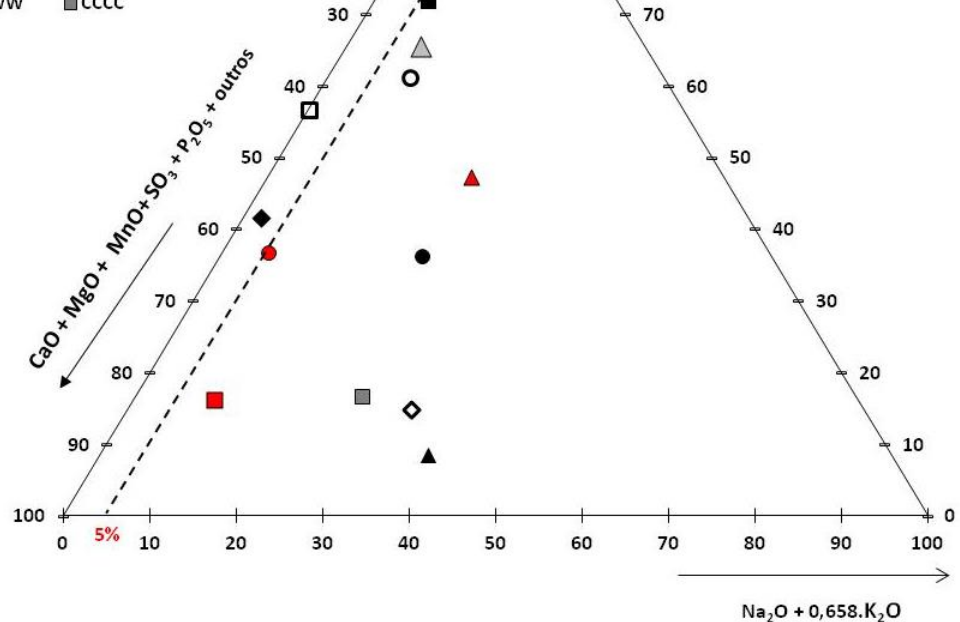

Figura 5 - DRX das cinzas CC e CF

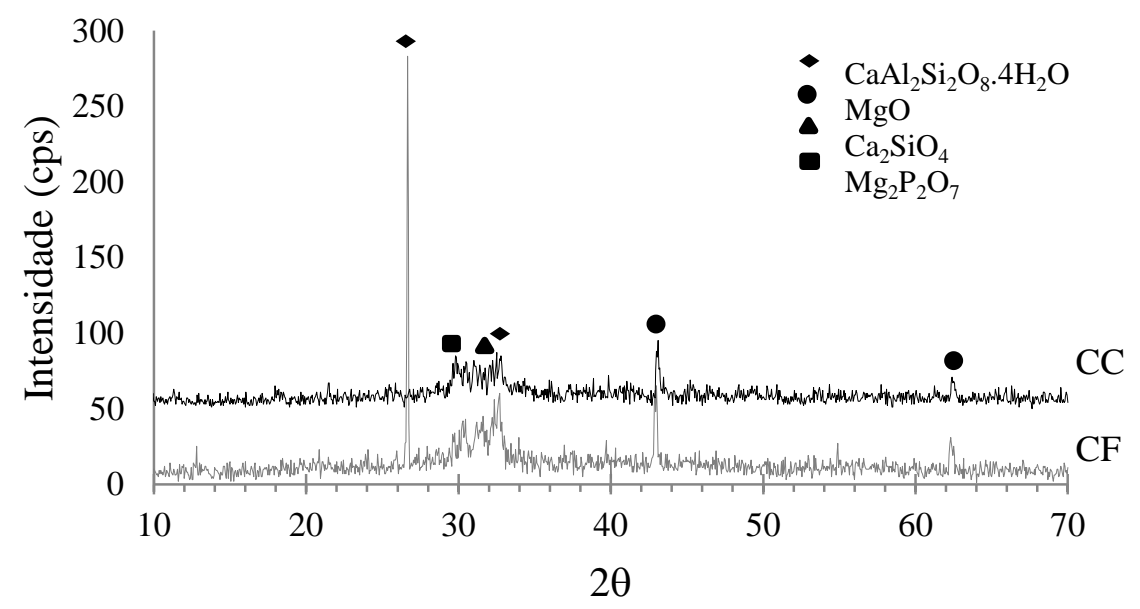

Figura 6 - Análise termogravimétrica da cinza ciclone (CC)

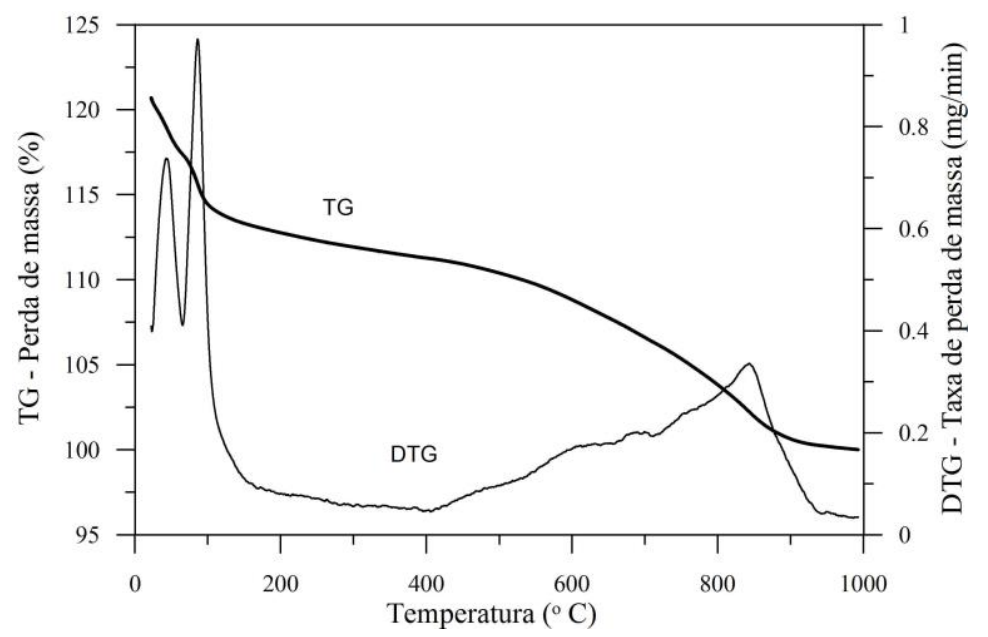

326 Silva, R. B.; Fontes, C. M. A.; Lima, P. R. L.; Gomes, O. da F. M.; Lima, L. G. L. M.; Moura, R. C. de A.; Toledo Filho, R. D. 


\section{Beneficiamento das cinzas}

A reatividade das adições minerais com o cimento Portland depende essencialmente de três fatores básicos: composição química, grau de cristalinidade e distribuição granulométrica das partículas.

Para melhorar o grau de amorfização da cinza de cacau, a cinza ciclone, que apresentava menor cristalinidade, foi submetida à queima controlada em temperaturas de $500{ }^{\circ} \mathrm{C}, 700{ }^{\circ} \mathrm{C}$ e $900{ }^{\circ} \mathrm{C}$. O grau de amorfização da cinza de cacau foi avaliado através de difractogramas de raios X, como mostra a Figura 7. Os difractogramas foram trasladados para permitir melhor visualização. Verifica-se que, mesmo após queima a $900{ }^{\circ} \mathrm{C}$, a cinza ainda apresentava picos cristalinos, o que não justifica o processo de calcinação dessa cinza para uso como adição mineral à argamassa. As curvas espectrais mostradas na Figura 8 demonstram uma variação na estrutura da cinza, notadamente nos picos entre 500 e $700 \eta \mathrm{m}$ e no pico próximo a 2.000 ๆm, mas ainda com manutenção da cristalinidade após a queima controlada.

A massa específica das cinzas foi medida em picnômetro a hélio, apresentando valores de 2,44 $\mathrm{kg} / \mathrm{dm}^{3}$ e $2,52 \mathrm{~kg} / \mathrm{dm}^{3}$ para as cinzas $\mathrm{CC}$ e $\mathrm{CF}$ respectivamente.

As curvas granulométricas das cinzas são apresentadas na Figura 9, juntamente com as curvas obtidas após a moagem em moinho de bolas pelos tempos de 1 min e $3 \mathrm{~min}$. Para moagem acima de 1 min para a cinza ciclone ou acima de 3 min para a cinza fornalha foi verificada sinterização da amostra que aderia ao jarro cerâmico do moinho, o que impedia a moagem.

\section{Figura 7 - Influência da temperatura sobre a cristalinidade da cinza ciclone}

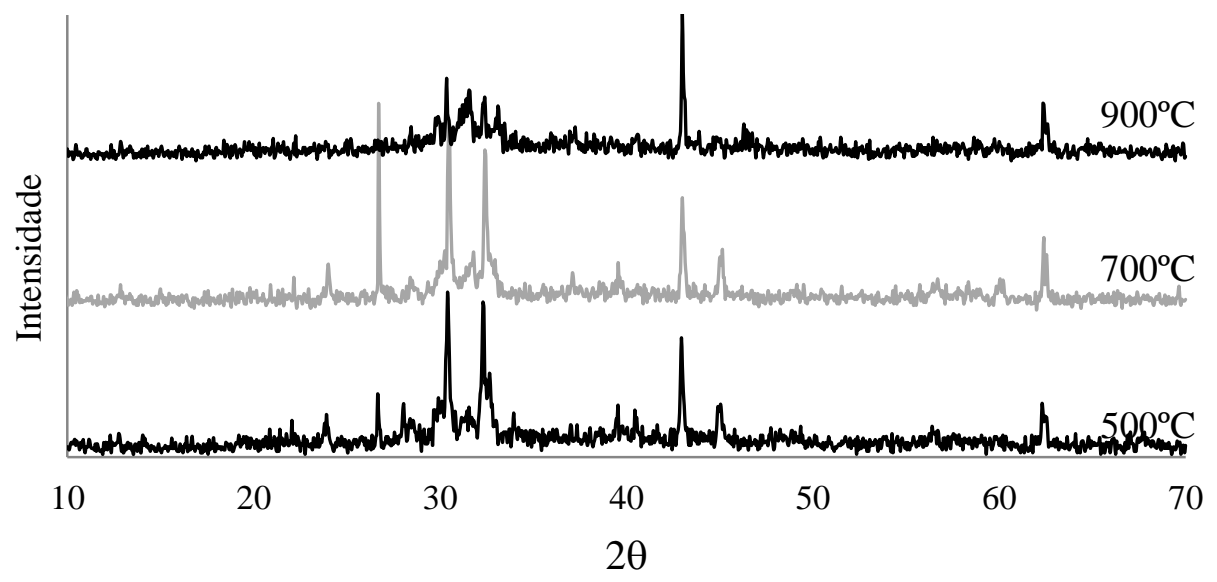

Figura 8 - Curvas espectrais da cinza ciclone após queima controlada

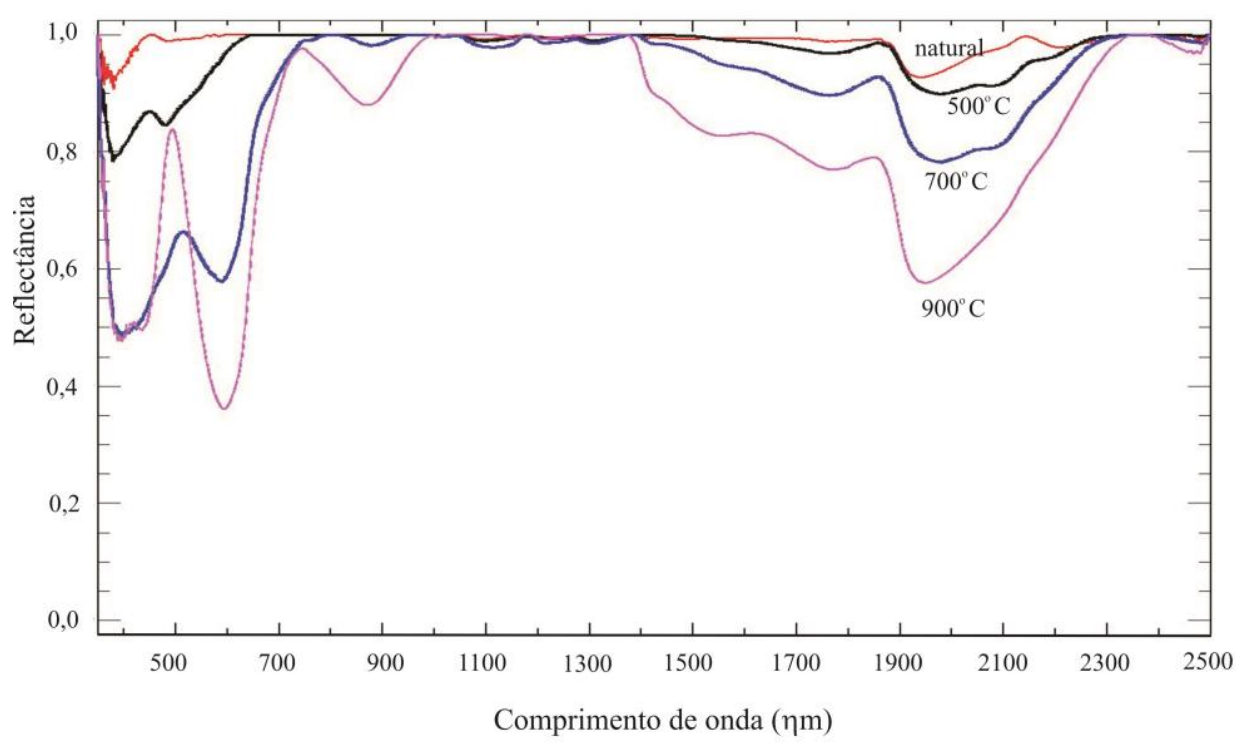


Figura 9 - Influência da moagem sobre a granulometria das cinzas
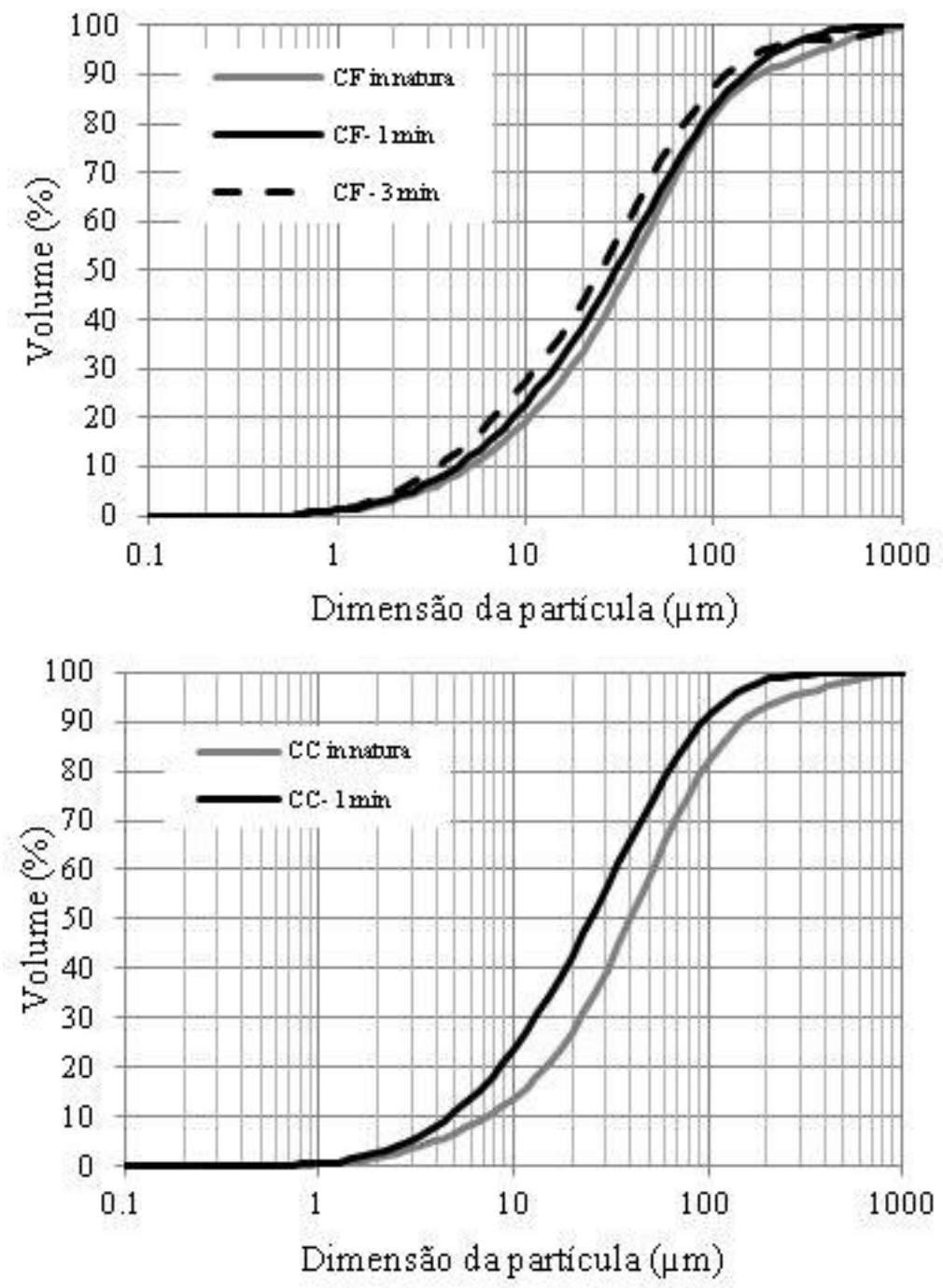

Verifica-se que, após a moagem de $1 \mathrm{~min}$, a cinza ciclone (CC) apresentou diâmetros $\mathrm{d}_{10}, \mathrm{~d}_{50}$ e $\mathrm{d}_{90} \mathrm{de}$ $5,01 \mu \mathrm{m}, 26,30 \mu \mathrm{m}$ e $104,71 \mu \mathrm{m}$ respectivamente, contra valores de 7,59 $\mu \mathrm{m}, 39,81 \mu \mathrm{m}$ e $158,49 \mu \mathrm{m}$ para a cinza in natura. Na Figura 9 observa-se que para a cinza fornalha $(\mathrm{CF})$ a moagem, mesmo com 3 min, não foi eficiente. O valor d50, por exemplo, variou de 34,67 para 26,30 $\mu \mathrm{m}$ após a moagem. Esse valor é similar ao da cinza ciclone com apenas $1 \mathrm{~min}$ de moagem, sendo este tempo definido como padrão para as cinzas utilizadas neste estudo.

Das cinzas ciclone e fornalha in natura e moídas foram obtidas imagens por microscopia de varredura eletrônica (MEV), apresentadas na Figura 10.
Pode ser observado que as partículas da cinza ciclone apresentam formato esférico e que as partículas da cinza fornalha apresentam formato irregular. Ambas apresentam grande rugosidade superficial, comportamento também relatado por Ban e Ramli (2011) com cinzas de madeira. As cinzas CF, quando submetidas à moagem, passaram a apresentar aspecto lamelar com camadas sobrepostas, o que pode acarretar diminuição da trabalhabilidade de argamassas no estado fresco, além de também aumentar o consumo de água, quando da utilização delas. A análise EDS, mostrada na Figura 11, realizada durante o ensaio de microscopia confirma a presença do potássio como elemento principal da composição química das cinzas. 
Figura 10 - Microscopia eletrônica de varredura (MEV) das cinzas ciclone e fornalha in natura e moída
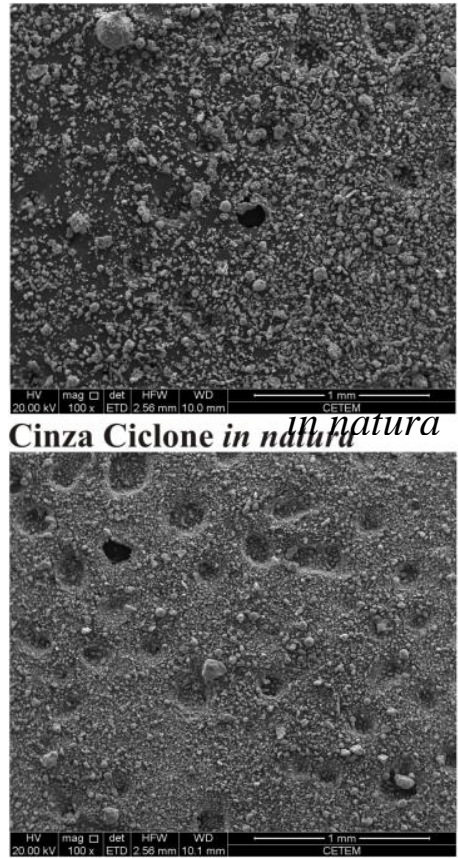

Cinza Ciclone moída por $1 \mathrm{~min}$

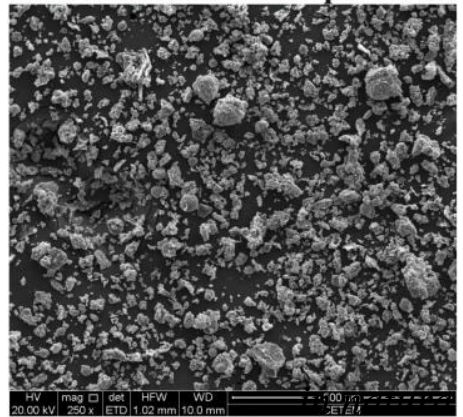

Cinza Fornalha in natura

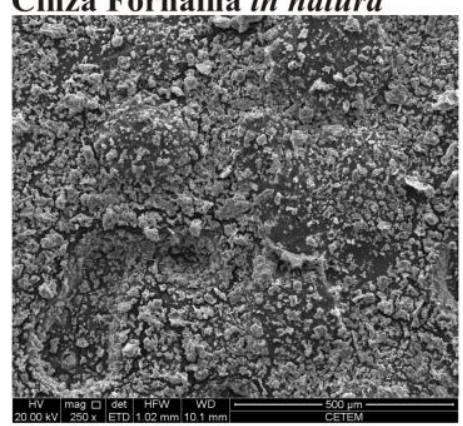

Cinza Fornalha moída por 1 min

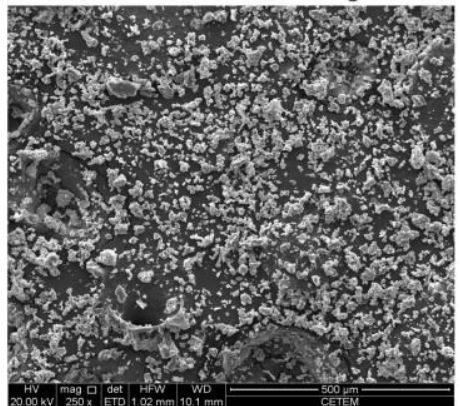

Cinza Fornalha moída por 3 min
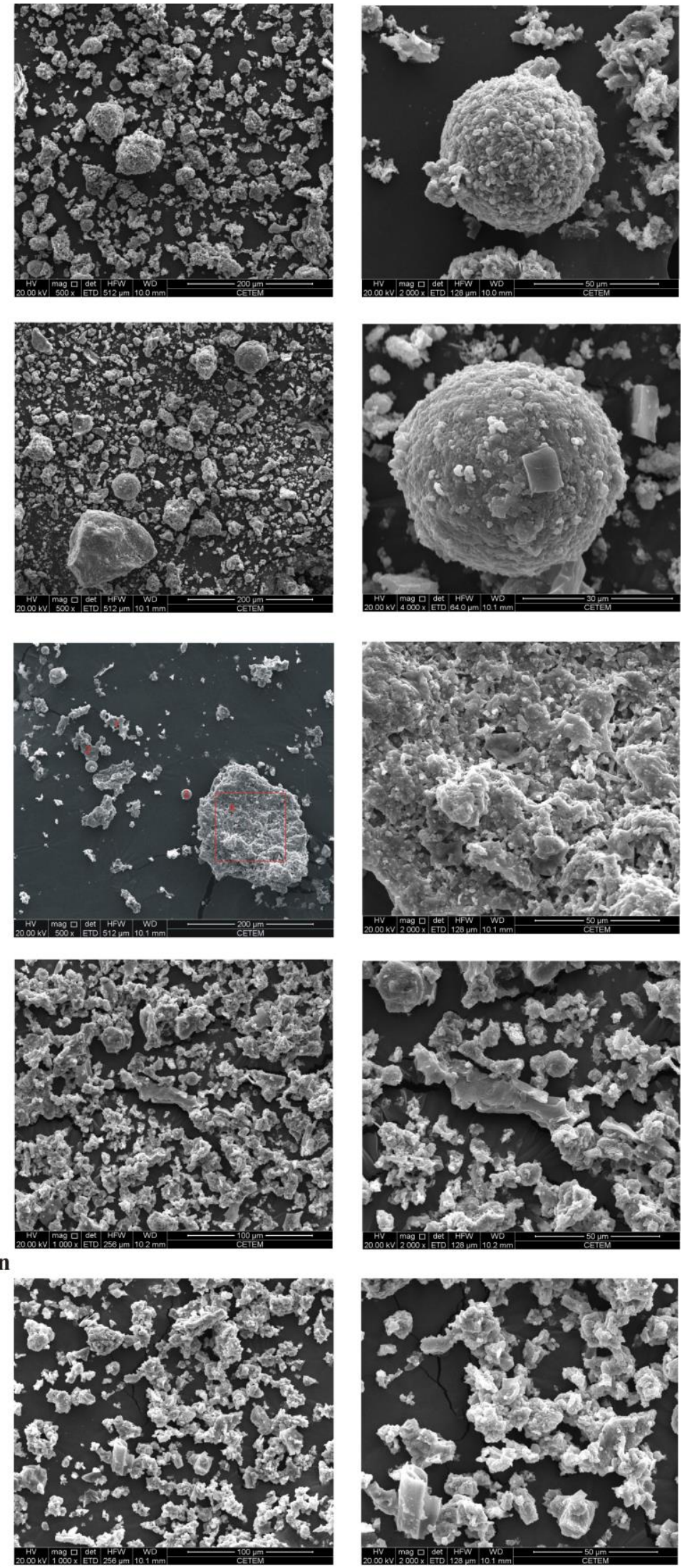
Figura 11 - Espectros de EDS obtido na microscopia eletrônica de varredura (MEV): (a) cinza ciclone; e (b) cinza fornalha

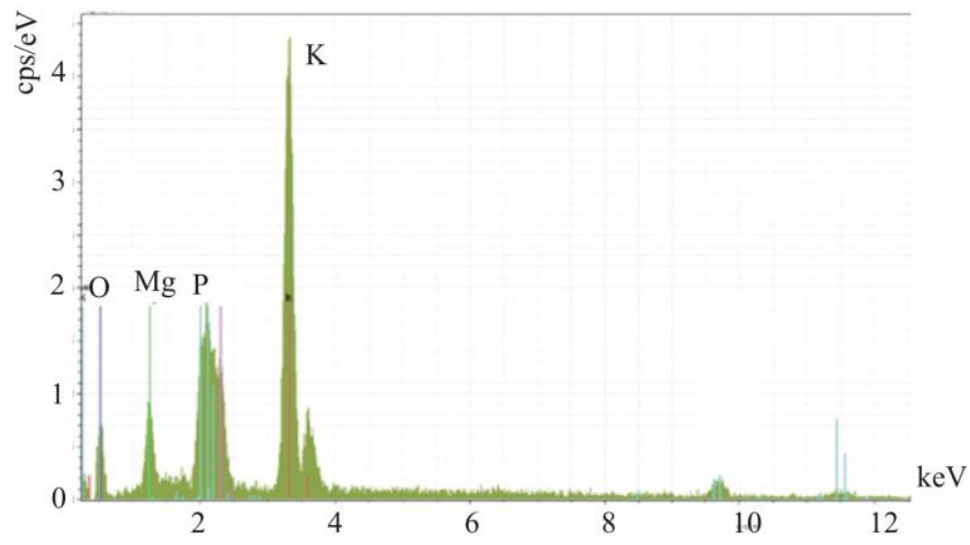

a) Cinza Ciclone

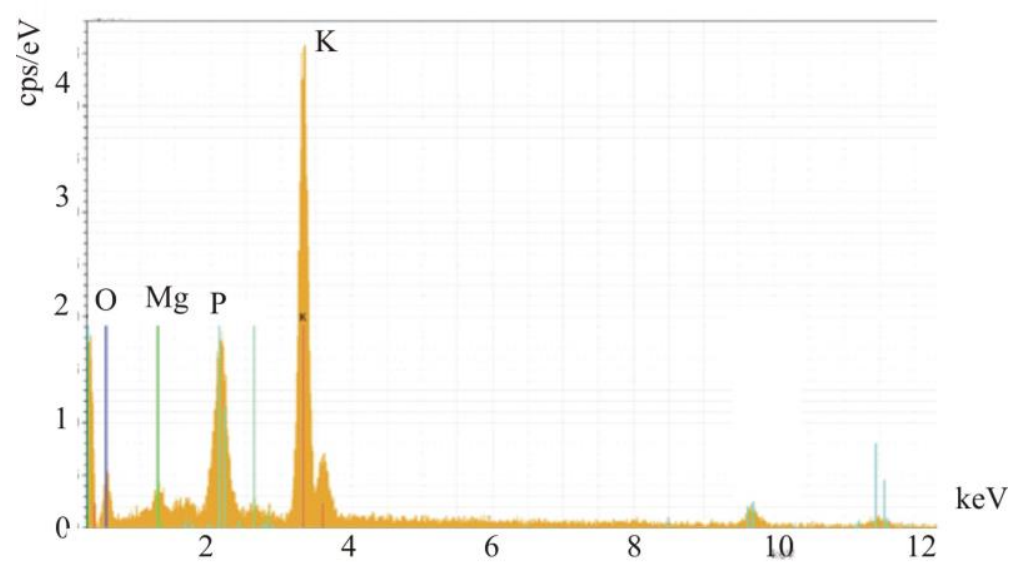

b) Cinza Fornalha

\section{Avaliação das argamassas}

Os resultados dos ensaios físicos e mecânicos das argamassas são apresentados nas Tabelas 2 e 3.

A adição de cinzas resulta no incremento de até $15 \%$ na absorção de água e de até $12 \%$ no índice de vazios das argamassas. Esse fato pode estar associado à maior rugosidade das cinzas, que consequentemente reteve mais água na mistura, gerando maior quantidade de vazios na argamassa endurecida. A massa específica apresentou variação máxima de $3 \%$ com a adição de cinza.

Comparando-se o tipo de cinza e o efeito da moagem, verifica-se que não há diferença importante entre as propriedades físicas para as diversas argamassas. A cinza fornalha foi a que apresentou maior absorção e maior índice de vazios. A massa específica apresentou redução com a utilização de cinza, o que pode ser atribuído ao aumento do índice de vazios e à menor densidade das cinzas relativamente à massa específica do cimento.

Os resultados da Tabela 3 indicam que a resistência mecânica das argamassas depende do tipo de cinza e da moagem. Na Figura 12 é mostrada a resistência à compressão das argamassas com cinzas com relação à resistência à compressão da argamassa de referência. Observase que a influência das cinzas sobre a resistência à compressão varia com o tipo e a moagem da cinza e com a idade da argamassa.

Para 3 dias de idade as argamassas com cinza apresentam resistência equivalente ou mesmo superior à referência. Para 7 dias, no entanto, a cinza proporciona uma redução importante na resistência, a qual é compensada aos 28 dias. Isso indica, como mostra a Figura 13, que a evolução da resistência à compressão da argamassa com cinza é maior entre a idade de 7 dias e 28 dias, enquanto a argamassa de referência atinge $94 \%$ de sua resistência já aos 3 dias de idade. 
Tabela 2 - Resultados de ensaios físicos das argamassas

\begin{tabular}{lrlrlcc}
\hline Mistura & \multicolumn{2}{c}{ Absorção (\%) $(\mathbf{C V})$} & \multicolumn{2}{c}{ Índice de Vazios $(\%)(\mathbf{C V})$} & \multicolumn{2}{c}{ Massa Específica $\left(\mathbf{g} / \mathbf{c m}^{\mathbf{3}}\right)(\mathbf{C V})$} \\
\hline REF & 7,89 & $(0,46)$ & $15,73(0,34)$ & 2,15 & $(0,09)$ \\
CC & 8,95 & $(0,88)$ & $17,25(1,14)$ & 2,10 & $(0,55)$ \\
CC M & 9,02 & $(0,92)$ & 17,49 & $(0,52)$ & 2,11 & $(0,40)$ \\
CF & 9,20 & $(0,95)$ & $17,60(0,76)$ & 2,09 & $(0,12)$ \\
CF M & 9,13 & $(0,42)$ & 17,40 & $(0,70)$ & 2,08 & $(0,44)$ \\
\hline
\end{tabular}

Nota: ${ }^{*} \mathrm{CV}$ : coeficiente de variação, em \%.

Tabela 3 - Resultados de ensaios mecânicos das argamassas

\begin{tabular}{lcccccc}
\hline \multirow{2}{*}{ Mistura } & \multicolumn{2}{c}{ Compressão (MPa) $(\mathbf{C V})$} & \multicolumn{3}{c}{ Tração na flexão (MPa) (CV) } \\
\cline { 2 - 7 } & 3 dias & 7 dias & 28 dias & 3 dias & 7 dias & 28 dias \\
\hline REF & $10,17(9,6)$ & $23,75(7,5)$ & $25,25(4,3)$ & $4,78(2,2)$ & $6,26(7,3)$ & $6,75(1,6)$ \\
CC & $10,70(5,6)$ & $16,75(6,2)$ & $21,37(3,3)$ & $3,88(3,6)$ & $4,97(5,4)$ & $5,91(7,3)$ \\
CC M & $10,40(4,2)$ & $18,72(7,0)$ & $24,74(4,0)$ & $4,65(1,6)$ & $5,83(8,7)$ & $6,79(4,1)$ \\
CF & $11,22(6,1)$ & $17,27(2,4)$ & $20,47(4,3)$ & $4,34(7,1)$ & $6,17(1,5)$ & $6,28(2,4)$ \\
CF M & $13,50(3,6)$ & $16,06(2,5)$ & $20,72(7,9)$ & $4,53(9,8)$ & $5,02(9,3)$ & $6,02(11,0)$ \\
\hline
\end{tabular}

Nota: *CV: coeficiente de variação, em \%.

Figura 12 - Efeito da adição de cinza sobre a resistência à compressão da argamassa de referência

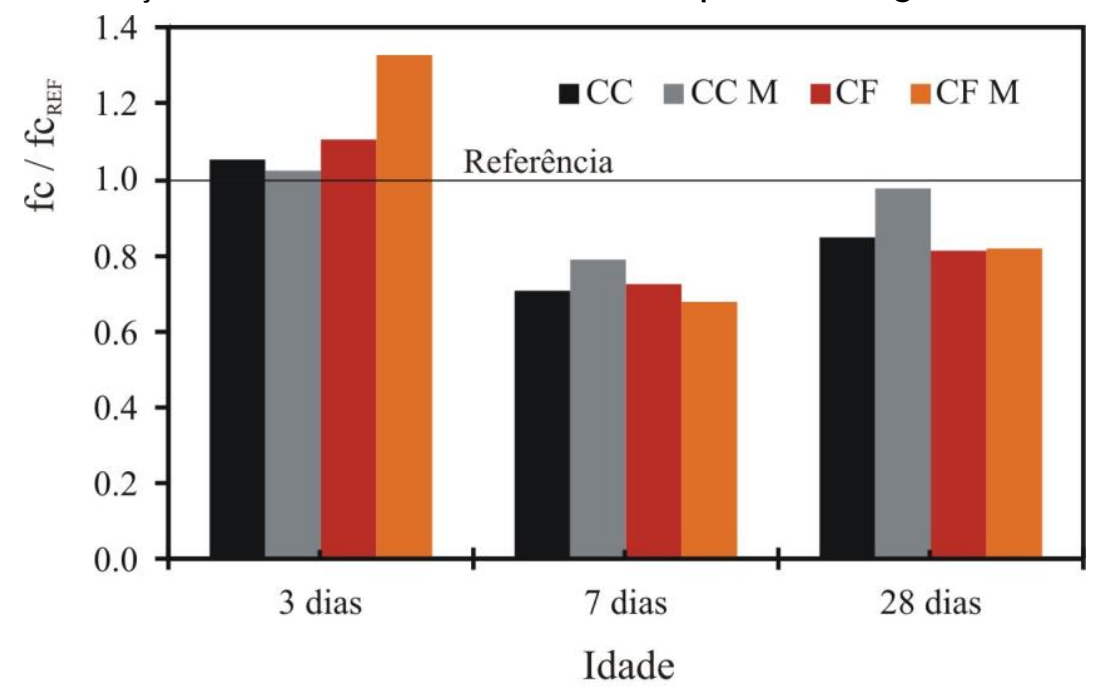

Figura 13 - Evolução da resistência à compressão das argamassas relativas à argamassa de referência aos 28 dias

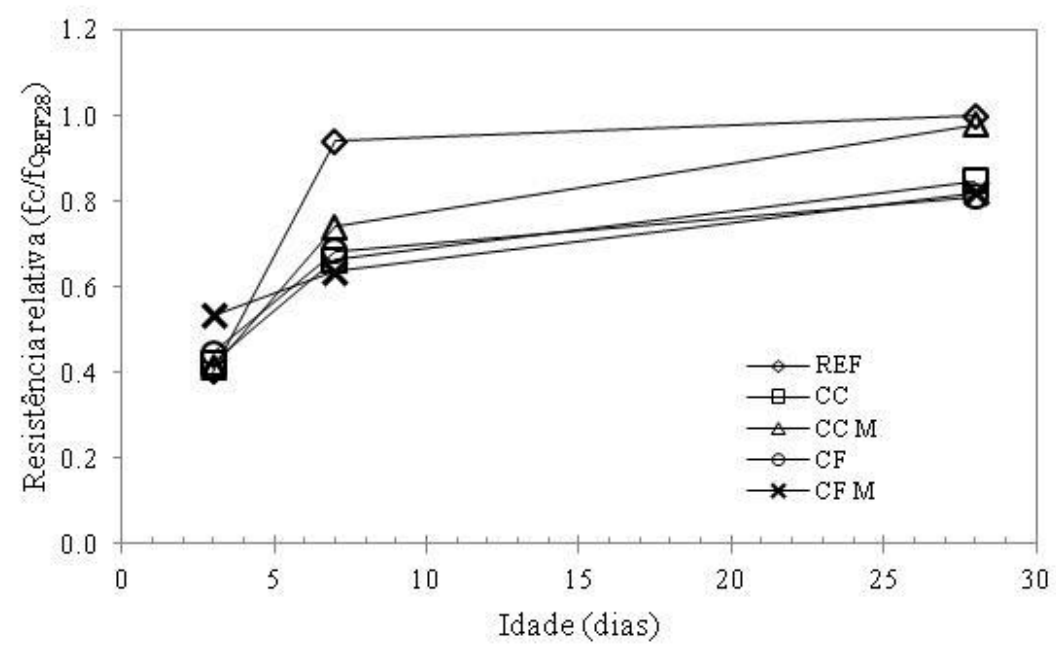


A influência do tipo de cinza e moagem sobre a resistência à compressão aos 28 dias de idade foi avaliada através de uma comparação estatística de pares de médias (Teste de Tukey). A Tabela 4 demonstra que apenas quatro pares mostraram-se estatisticamente iguais, ou seja, não demonstraram diferença significativa (ns). A igualdade de resistência entre as misturas REF e CC M indica que o cimento pode ser substituído pela cinza ciclone moída sem danos mecânicos.

A moagem da cinza ciclone (mostrada na Figura 9), de fato, melhora o comportamento da argamassa produzida com essa cinza (CC M), com aumento da resistência à compressão quando comparado à mistura com cinza ciclone in natura (CC). A moagem da cinza fornalha, por outro lado, não conseguiu potencializar a ação da argamassa. A diferença de resistência entre as argamassas contendo essas cinzas ( $\mathrm{CF}$ e $\mathrm{CF} \mathrm{M}$ ) resultou não significativa. Comparando-se as resistências das argamassas com cinza ciclone e cinza fornalha (CC e CF) é verificado que o tipo de cinza, sem moagem, não afeta a resistência à compressão.

A resistência à tração apresentou comportamento semelhante à resistência à compressão, com a argamassa contendo cinza ciclone mantendo a mesma resistência aos 28 dias que a argamassa de referência e a redução de resistência para as demais argamassas. É importante ressaltar que as cinzas de biomassa de cacau não apresentam teores de sílica e alumina em sua composição que permitam o desenvolvimento de atividades pozolânicas; dessa forma, assim como argamassas feitas com cinzas de composição química semelhante (LIMA; ROSSIGNOLO, 2009), é esperada redução de resistência mecânica pela redução do teor de cimento.

\section{Conclusões}

Neste trabalho foram coletados e caracterizados dois tipos de cinza de biomassa, oriundos da indústria de beneficiamento de cacau, com o objetivo de avaliar sua potencialidade como adição mineral em argamassas, em substituição a 5\% do cimento.

A caracterização morfológica da cinza demonstrou que ela apresenta textura rugosa e superfície porosa, o que pode ter influenciado o aumento da absorção de água das argamassas feitas como essa cinza.

A partir da análise química foi possível identificar que a cinza ciclone e a cinza fornalha não apresentam compostos químicos que permitam o desenvolvimento de atividades pozolânicas com os compostos hidratados do cimento. Além disso, sua estrutura mineralógica mantém-se cristalina mesmo após a calcinação da cinza a altas temperaturas, o que limita sua reatividade química. Devido a isso, a utilização de cinza ciclone e da cinza fornalha in natura resultou em redução da resistência mecânica.

No entanto, a moagem da cinza ciclone durante 1 min permitiu a redução do diâmetro médio das cinzas, o que fortaleceu o efeito de empacotamento da mistura e resultou no aumento da resistência mecânica da argamassa com relação à argamassa com cinza sem moagem. Comparando com a resistência mecânica da argamassa de referência, a resistência à compressão desta argamassa mostrouse estatisticamente igual.

Verifica-se assim que a cinza de biomassa estudada pode ser inserida como elemento inerte em materiais à base de cimento, indicando uma destinação adequada do resíduo com o potencial de reduzir a extração de materiais naturais utilizados para esse fim.

Tabela 4 - Análise da diferença entre médias de resistência à compressão aos 28 dias (Teste de Tukey)

\begin{tabular}{lccc}
\hline Pares de misturas & Diferença (MPa) & Q & (p) \\
\hline & Resistência à compressão & \\
\hline REF - CC & 3,8819 & 7,1436 & $<0,01$ \\
REF - CC M & 0,5149 & 1,0593 & $\mathrm{~ns}$ \\
REF - CF & 4,7814 & 10,1599 & $<0,01$ \\
REF - CF M & 4,3519 & 8,5613 & $<0,01$ \\
CC - CC M & 3,3671 & 6,9275 & $<0,01$ \\
CC - CF & 0,8994 & 1,9112 & $\mathrm{~ns}$ \\
CC - CF M & 0,4699 & 0,9245 & $\mathrm{~ns}$ \\
CC M - CF & 4,2665 & 10,5866 & $<0,01$ \\
CC M - CF M & 3,8370 & 8,5942 & $<0,01$ \\
CF - CF M & 0,4295 & 0,9998 & $\mathrm{~ns}$ \\
\hline
\end{tabular}

Nota: ${ }^{*}$ ns = não significativa. 


\section{Referências}

ASSOCIAÇÃO BRASILEIRA DE NORMAS TÉCNICAS. NBR 5752: materiais pozolânicos: determinação de atividade pozolânica com cimento Portland: índice de atividade pozolânica com cimento. Rio de Janeiro, 2012.

AL-AKHRAS, N. M. Durability of Wheat Straw ash Concrete to Alkali-Silica Reaction.

Proceedings of the Institution of Civil Engineers Construction Materials, v. 166, p.65-70, 2013.

ALEXPOULOS, D. et al. Mine Wastewater Tretament by Highly Calcareous and Siliceous Fly Ash: a comprative study. In: 2013 WORLD OF COAL ASH CONFERENCE, Lexington, 2013. Anais... Lexington, 2013.

AMERICAN SOCIETY FOR TESTING AND MATERIALS. C 618: coal fly ash and raw or calcined natural pozzolanfor use as a mineral admixture in concrete. 2001.

\section{ASSOCIAÇÃO BRASILEIRA DE NORMAS}

TÉCNICAS. NBR 13276: argamassa para assentamento e revestimento de paredes e tetos: preparo da mistura e determinação do índice de consistência. Rio de Janeiro, 2003.

ASSOCIAÇÃO BRASILEIRA DE NORMAS TÉCNICAS. NBR 13279: argamassa para assentamento e revestimento de paredes e tetos: determinação da resistência à tração na flexão e à compressão. Rio de Janeiro, 2005b.

\section{ASSOCIAÇÃO BRASILEIRA DE NORMAS} TÉCNICAS. NBR 9778: argamassa e concreto endurecido: determinação da absorção de água, índice de vazios e massa específica. Rio de Janeiro, 2005a.

BAN, C. C.; RAMLI, M. The Implementation of Wood Waste Ash as a Partial Cement Replacement Material in the Production of Structural Grade Concrete and Mortar: an overview Resources, Conservation and Recycling, v. 55, n. 7, p.669$685,2011$.

CARRASCO, B. et al. An Evaluation of Bottom Ash From Plant Biomass as a Replacement For Cement in Building Blocks. Fuel, v. 118, n. 15, p. 272-280, 2014.

CORDEIRO, G. C., TOLEDO FILHO, R. D.; FAIRBAIRN, E. M. R . Caracterização de Cinza do Bagaço de Cana-de-Açúcar Para Emprego Como Pozolana em Materiais Cimentícios. Quimica Nova, v. 32, n. 1, p. 82-86, 2009 b.
CORDEIRO, G. C.; TOLEDO FILHO, R. D.; FAIRBAIRN, E. M. R. Influência da Substituição Parcial de Cimento Por Cinza Ultrafina da Casca de Arroz Com Elevado Teor de Carbono nas Propriedades do Concreto. Ambiente Construído, Porto Alegre, v. 9, n. 4, p. 99-107, 2009a.

CUENCA, J. et al. Effects of Olive Residue Biomass Fly Ash as Filler in Self-Compacting Concrete. Construction and Building Materials, v. 40, p. 702-709, 2013.

ESTEVES, T. C. et al. Use of Biomass Fly Ash For Mitigation of Alkali-Silica Reaction of Cement Mortars. Construction and Building Materials, v. 26, n. 1, p. 687-693, 2012.

EUROPEAN STANDARD. EN 450-1: fly ash for concrete: part 1: definitions, specifications and conformity criteria. Brussels, 2001.2012

FONTES, C. M. A. Utilização das cinzas de lodo de esgoto e de resíduo sólido urbano em concretos de alto desempenho. Rio de Janeiro. 2008. Tese (Doutorado em Engenharia Civil) Programa de Pós-Graduação em Engenharia Civil, Universidade Federal do Rio de Janeiro, Rio de Janeiro, 2008.

GREENPACE BRASIL. Revolução Energética: perspectivas para uma energia global sustentável. 2007.

KANNING, R. C. et al. Banana Leaves Ashes as Pozzolan For Concrete and Mortar of Portland Cement. Construction and Building Materials, n. 54, p. 460-465, 2014.

KANNING, R. C. Utilização da cinza de folha de bananeira como adição em argamassas de cimento Portland. Curitiba, 2013. Tese (Doutorado em Engenharia Civil) - Escola de Engenharia, Universidade Federal do Paraná, Curitiba, 2013.

LEIVA, C. et al. Fire Resistance of Biomass Ash Panels Used For Internal Partitions in Buildings. Fire Safety Journal, v. 44, n. 4, p. 622-628, 2009.

LIM, J. S. et al. A Review on Utilisation of Biomass From Rice Industry as a Source of Renewable Energy. Renewable and sustenaible energy reviews, v. 16, p. 3084-3094, 2012.

LIMA, S. A.; ROSSIGNOLO, J. A. Análise da Pozolanicidade da Cinza da Casca da Castanha do Caju Pelo Método de Difratometria de Raios X. Revista Matéria, v. 14, n. 1, p. 680-688, 2009.

NAIR, D. G. et al. A Structural Investigation Relating to the Pozzolanic Activity of Rice Husk Ashes. Cement and Concrete Research, v. 38, n.6, p. 861-869, 2008. 
OLIVEIRA, D. et al. Characterization and Use of Swine Deep Bedding Ashes in Cementitious Composites. Engenharia Agrícola, v. 32, n. 5, p. 810-821, 2012.

PINHEIRO, G. F.; RENDEIRO, G.; PINHO, J. T. Densidade Energética de Resíduos Vegetais.

Biomassa \& Energia, v. 2, n. 2, p. 113-123, 2005.

RODRIGUES, M. S. et al. Cinza de Palha de Cana-de-Açúcar Como Adição Mineral em Fibrocimento. Revista Brasileira de Engenharia Agricola e Ambiental, v. 17, n. 12, p. 1347-1354, 2013.

\section{SODRÉ, G. A. Substratos e Estaquia na}

Produção de Mudas de Cacaueiro. Jaboticabal, 2007. Tese (Doutorado em Agronomia) - Escola de Engenharia, Universidade Estadual Paulista Júlio de Mesquita Filho, Jaboticabal, 2007.

TANGCHIRAPAT, W.; JATURAPITAKKUL, C. Strength, Drying Shrinkage, and Water Permeability of Concrete Incorporating Ground Palm Oil Fuel Ash. Cement and Concrete Composites, v. 32, n. 10, p. 767-774, 2010.

TEODORO, P. E. et al. Comportamento FísicoMecânico do Concreto Com Substituição de Cimento Portland Por Cinzas do Bagaço de Canade-Açúcar. REEC - Revista Eletrônica de Engenharia Civil, v. 6, n. 2, p. 22-27, 2013.
VASSILEV, S. V. et al. An Overview of the Chemical Composition of Biomass. Fuel, v. 89, n. 5, p. 913-933, 2010.

VASSILEV, S. V. et al. An Overview of the Composition and Application of Biomass Ash: part 1, phase-mineral and chemical composition and classification. Fuel, v. 105, p. 40-76, 2013.

VILLAR-COCIÑA, E. et al. Pozzolanic Behavior of Bamboo Leaf Ash: characterization and determination of the kinetic parameters. Cement and Concrete Composites, v. 33, n. 1, p. 68-73, 2011.

WERTHER, J. et al. Combustion of Agricultural Residues. Progress in Energy and Combustion Science, v, 26, p. 1-27, 2000.

WORLD ENERGY ASSESSMENT. Energy and the Challenge of Sustainability. United Nations Development Programme, United Nations Development of Economic and Social Affairs and World Energy Council, 2000.

\section{Agradecimentos}

Os autores agradecem a CAPES pela bolsa de mestrado do primeiro autor e à FAPESB pelo apoio financeiro ao projeto (PET 0010/2012).

\section{Rebeca Bastos Silva}

Programa de Pós-Graduação em Engenharia Civil e Ambiental | Universidade Estadual de Feira de Santana | Av. Transnordestina, s/n, Novo Horizionte | Feira de Santana - BA - Brasil | CEP 44036-900 | Tel.: (75) 31618310 | E-mail: eng.rebastos@gmail.com

\section{Cintia Maria Ariani Fontes}

Departamento de Tecnologia | Universidade Estadual de Feira de Santana | E-mail: cintiafontes@gmail.com

Paulo Roberto Lopes Lima

Departamento de Tecnologia | Universidade Estadual de Feira de Santana | Tel.: (75) 3161-8117 | E-mail: lima.prl.uefs@gmail.com

\section{Otavio da Fonseca Martins Gomes}

Centro de Tecnologia Mineral | Av. Pedro Calmon 900, Itha do Fundão | Rio de Janeiro - RJ - Brasil | CEP 21941-908 | Tel: (21) 3865-7266 | E-mail: ogomes@gmail.com

\section{Lilian Graicy Lima Morais Lima}

Departamento de Ciências Extatas | Universidade Estadual de Feira de Santana | Tel.: (75) 31618086 | E-mail: graicylima@gmail.com

\section{Ruan Carlos de Araujo Moura}

Departamento de Ciências Exatas e Tecnlógicas | Universidade Estadual de Santa Cruz | Rodovia Ilhéus-Itabuna, km 16 | Ilhéus - BA Brasil | CEP: 45662-000 | Tel: (73) 36805106 | E-mail: ruan_moura@yahoo.com.br

\section{Romildo Dias Toledo Filho}

Centro de Tecnologia | Universidade Federal do Rio de Janeiro | Caixa Postal 68506 | Rio de Janeiro - RJ - Brasil | CEP $21941-972$ | Tel.: (021) 2562-8474 | E-mail: toledo@labest.coc.ufrj.br

\section{Revista Ambiente Construído}

Associação Nacional de Tecnologia do Ambiente Construído

Av. Osvaldo Aranha, $99-3^{\circ}$ andar, Centro

Porto Alegre - RS - Brasil

CEP 90035-190

Telefone: +55 (51) 3308-4084

Fax: +55 (51) 3308-4054

www.seer.ufrgs.br/ambienteconstruido

E-mail: ambienteconstruido@ufrgs.br 